\title{
O BALANCED SCORECARD NO PLANEJAMENTO ESTRATÉGICO DA ADMINISTRAÇÃO PÚBLICA
}

\section{ARTIGO ORIGINAL}

OLIVEIRA, Maria Rosa de ${ }^{1}$

OLIVEIRA, Maria Rosa de. O Balanced Scorecard no planejamento estratégico da administração pública. Revista Científica Multidisciplinar Núcleo do Conhecimento. Ano 06, Ed. 06, Vol. 04, pp. 44-52. Junho de 2021. ISSN: 2448-0959, Link de

acesso:

https://www.nucleodoconhecimento.com.br/administracao/estrategico-daadministracao,

DOI: 10.32749/nucleodoconhecimento.com.br/administracao/estrategico-da-administracao

\section{RESUMO}

Este artigo tem como finalidade falar da administração Pública e a necessidade de se estabelecer uma maneira eficiente de planejamento estratégico, com o objetivo de utilizar de forma benéfica os recursos públicos, atendendo sempre à necessidade da população. A metodologia utilizada foi a revisão bibliográfica. $O$ recurso abordado, neste artigo, foi o Balanced Scorecard - BSC, uma ferramenta de monitoramento de desempenho e de análise da estratégica empregada para a criação de valor na gestão pública. Procuramos evidenciar sua funcionalidade e os benefícios do acesso à essa ferramenta no planejamento estratégico de uma gestão pública. Ademais, cumpriu esclarecer a evolução histórica da Administração Pública, bem como seu conceito e a conceituação do BSC, para que fosse possível estabelecer uma aliança entre a gestão e a ferramenta. Ao final, concluímos que é

\footnotetext{
${ }^{1}$ Ensino Superior Completo, Pós- graduação - Incompleta.
}

RC: 87947

Disponível em:

https://www.nucleodoconhecimento.com.br/administracao/estrategico-da- 
de suma importância que haja planejamento estratégico nos processos de gestão da administração pública, para isso, ferramentas como o BSC podem ser utilizadas, garantindo melhor eficiência da administração e celeridade das ações.

Palavras-chave: Administração Pública, BSC, Planejamento Estratégico.

\section{INTRODUÇÃO}

A gestão pública nacional convive com um ambiente de muita limitação e carência de recursos e ferramentas, bem como outros fatores já conhecidos, como o crescimento de gastos do setor, a necessidade da implementação de melhor qualidade nos serviços de atendimento à população, além da perda de confiança da sociedade na administração pública.

Neste sentido, o setor público de caracteriza como sendo um segmento cheio de complexidades, tendo em vista que seus resultados são medidos pela satisfação da população que é usuária dos seus serviços.

Todavia, é de suma importância um levantamento e a mensuração de resultados para o controle da gestão, para que se possa atuar na melhoria em diversos aspectos que contribuam no acompanhamento, na avaliação e no aperfeiçoamento da gestão pública.

E, para que haja uma eficiência neste monitoramento, focando a avaliação de toda a gestão, a administração utiliza de instrumentos que colaboram neste trabalho, de forma mais precisa e menos burocrática, como por exemplo o BALANCED SCORECARD - BSC, que se caracteriza por ser um sistema de monitoramento de desempenho, que proporciona à administração pública um referencial de análise da estratégica empregada para a criação de valor.

RC: 87947

Disponível em:

https://www.nucleodoconhecimento.com.br/administracao/estrategico-da- 
Diante disto, buscou este trabalho explicitar de forma clara e simples sobre a gestão pública em si e sobre a ferramenta supracitada.

\section{DESENVOLVIMENTO}

\subsection{DA ADMINISTRAÇÃO PÚBLICA E SUA EVOLUÇÃO HISTÓRICA}

Inicialmente, é imperioso conceituar a Administração Pública como sendo "a reunião de órgãos instituídos para consecução dos objetivos do Governo" (Meirelles, 2009, p. 65).

Todavia, o autor traz à baila com este conceito um sentido formal da Administração Pública, haja vista que se pode entender em sentido material, como sendo esta uma "junção das funções necessárias aos serviços públicos em geral", segundo o mesmo autor (MEIRELLES, 2009).

Ademais, há de se tratar em sua operacionalização, que pode ser conceituada segundo Meirelles (2009, p. 66) como "o desempenho perene e sistemático, legal e técnico, dos serviços próprios do Estado ou por ele assumidos em benefício da coletividade".

Neste sentido, numa ótica mais ampla do conceito da Administração Pública, podese dizer que se trata de todo aparelhamento utilizado pelo Estado, que se direciona à realização dos serviços, com a finalidade de atender os anseios e necessidades da população.

Sendo assim, destaca-se a participação do Estado como responsável pela prestação de diversos serviços, que são necessidade da população, como a educação, saúde, segurança, lazer, esporte, habitação, assistência social, obras, infraestrutura, entre outros. Mas para que todos sejam executados de forma ordenada e com qualidade,

RC: 87947

Disponível em:

https://www.nucleodoconhecimento.com.br/administracao/estrategico-da- 
cabe a própria administração gerir bem os recursos existentes, atuando de forma célere, transparente e eficiente (SANTOS, 2017).

Logo, pode-se definir a Administração Pública, conforme aduz Castro (2020, s/p) "como um conjunto de órgãos e servidores responsáveis por atender as necessidades da sociedade, ou seja, aqueles que são responsáveis pela gestão de algo público e seus desdobramentos."

Neste contexto, vê-se uma grande evolução histórica acerca do entendimento de Administração Pública, tendo em vista que se substitui um modelo anterior, que se considerava ultrapassado, inserindo novos conceitos e priorizando os procedimentos de aprimoramento dos serviços que são prestados pelo Estado à população, representados pela Administração Pública Gerencial, Patrimonial e Burocrática, que em pleno funcionamento conseguem suprir todas as necessidades do Estado (CASTRO, 2020).

Segundo Castro (2020, s/p):

Em cada modelo está representado um contexto histórico. Incialmente, observa-se a inclusão das ideias patrimonialistas na administração pública brasileira, seguido da introdução de premissas da burocracia weberiana, finalizando com as características da administração gerencial. Contudo, é quase que unânime a não existência de uma sobreposição total de um modelo sobre os demais, na atualidade.

Ressalte-se que esses modelos, com o passar do tempo, foram sendo aperfeiçoados e, se inserindo na administração conforme as demandas atuais, porém ainda existem práticas antigas sendo utilizadas conjuntamente com práticas atuais, de acordo com as novas rotinas administrativas (CASTRO, 2020).

\subsection{DO BALANCED SCORECARD - BSC E SUA APLICABILIDADE NA ADMINISTRAÇÃO PÚBLICA}

RC: 87947

Disponível em:

https://www.nucleodoconhecimento.com.br/administracao/estrategico-da- 
O Balanced Scorecard (BSC) teve seu surgimento pelo início da década de 1990, por Robert Kaplan e David Norton, no instituto Nolan Norton, que tem por intuito alinhar as estratégias de demandas, sejam internas ou externas, através de indicadores verificáveis e quantitativos (KAPLAN; NORTON, 1997).

Neste sentido, Prado (2002, p. 36) relata que "o BSC é uma ferramenta que busca sanar a preocupação dos executivos em relação a seus objetivos e o cumprimento destes, partindo da definição de que o BSC é uma ferramenta que mensura a totalidade da empresa."

Ou seja, pode-se dizer que, trata-se de uma ferramenta onde gestores traçam estratégias, com base numa visão holística de seus negócios, seja ele privado ou público, proporcionando às organizações um status de crescimento e de melhoria com maior constância (ADMINISTRADORES, 2014).

Martins (2010) afirma que o Balanced Scorecard é um modelo de avaliação de desempenho organizacional que procura ir além das informações produzidas pelos indicadores financeiros tradicionais. Todavia estes indicadores por si só, são incapazes de avaliar os impulsionadores de rentabilidade no longo prazo. $\mathrm{O}$ autor ainda acrescenta que o foco do BSC está nos objetivos da organização, na coordenação do processo individual de tomada de decisão e no estabelecimento de uma base sustentável para que ocorra o processo de aprendizagem organizacional.

Neste sentido, entende-se que o BSC mede o desempenho da organização em quatro perspectivas, a saber: a financeira, cliente/usuário, processos internos e aprendizagem e crescimento, ou seja, juntando as quatro perspectivas, a ferramenta busca indicar o perfil financeiro da organização, de forma à apontar melhorias no processo, reduzindo custos e traçando estratégias de ampliação, identificar o público alvo, em segmentos específicos da administração e, mensurando a satisfação, o desempenho e demais características que beneficiem o serviço. Além disso,

RC: 87947

Disponível em:

https://www.nucleodoconhecimento.com.br/administracao/estrategico-da- 
consegue identificar os processos críticos que devem ser melhorados na organização e identifica a infraestrutura necessária para abranger as melhorias, para que proporcione o crescimento e a eficiência dos serviços prestados pela administração (MARTINS, 2010).

Ghelman; Costa (2006) afirmam que:

Diferente das quatro perspectivas do BSC para o setor privado, na proposta de implantação para o setor público, constam três perspectivas do modelo tradicional: Finanças, Clientes e Processos, com a separação de Aprendizado e Crescimento em duas: uma perspectiva para Pessoas e outra para Modernização Administrativa. Com o objetivo de medir a efetividade das ações públicas, necessitou-se criar uma nova perspectiva chamada Cidadão/Sociedade.

Outrossim, cumpre esclarecer, como já supracitado que o BSC é uma ferramenta de planejamento estratégico e, sendo assim, a entidade deve traçar suas metas e estratégias, visando, desta forma, medir mais precisamente o desempenho organizacional.

Enquanto se fala de lucro na esfera privada, na administração pública, tal recurso é aplicado em relação à prestação de serviços oferecidos à população, fazendo com que o BSC seja adaptado a atender os preceitos inerentes ao setor público. (PINTO, 2004, apud REIS, 2019) analisam essa diferença entre as organizações privadas e públicas. A empresa direciona a sua performance para o retorno do capital investido pelos acionistas, colocando a perspectiva financeira no topo do BSC. E continuam analisando para as organizações públicas, a perspectiva financeira possui uma posição secundária, destacando a perspectiva dos clientes, seguida pelas demais: processos internos, aprendizagem e crescimento e, por último, a perspectiva financeira.

RC: 87947

Disponível em:

https://www.nucleodoconhecimento.com.br/administracao/estrategico-da- 
Ghelman; Costa (2006) aduzem que na administração pública é preciso demonstrar os benefícios, efeitos ou impactos diretos ou indiretos do exercício da atividade pública para o cidadão. Ademais, além de medir a melhoria da qualidade da prestação dos serviços para cliente, é necessário aferir se o cidadão/sociedade está satisfeito com a prestação de um serviço público.

Em outras palavras, os autores afirmam que cada organização deve transformar o modelo e aperfeiçoá-lo de acordo com a realidade e a necessidade administrativa daquela gestão, para que a precisão tenha um índice maior.

Em suma, a utilização do BSC pela administração pública, deve ser estabelecida em perspectivas que se adequem à necessidade do município/estado, mantendo sempre um equilíbrio em uma relação lógica de causalidade entre gestão e cidadão, a quem se serve, se configurem como a razão da existência da mensuração pela ferramenta e se obtenha resultados mais assertivos à realidade vivenciada (BERGUE, 2005).

\subsection{OS BENEFÍCIOS DO BSC}

O BSC é um modelo de gestão estratégica utilizada pelas organizações em busca de uma integração com os stekeholders (BERGUE, 2005). O autor ainda acrescenta que essa integração com a empresa, seja interna, seja externa, deve proporcionar um alinhamento com as metas estratégicas estabelecidas pela alta gestão.

Neste sentido, entende-se que todo o processo de utilização do BSC, terá resultados de médio à longo prazo, por ter como base a gestão e o quanto esta está disposta a atingir seus objetivos, pautados nas quatro perspectivas elencadas anteriormente (BERGUE, 2005).

RC: 87947

Disponível em:

https://www.nucleodoconhecimento.com.br/administracao/estrategico-da- 
Todavia, os benefícios trazidos pelo BSC são basicamente voltados à comunicação dentro da organização, com objetivo da redução de custos e das melhorias na performance, uma vez guiados pelos resultados obtidos através de dados quantitativos adquiridos pela ferramenta, que darão o apoio necessário à gestão de topo, a flexibilidade e adaptabilidade para a realidade do local (BERGUE, 2005).

Neste contexto, os benefícios para as organizações ou entidades que utilizam do BSC são variados.

Senão vejamos:

Tabela 1: Benefícios Do BSC Na Administração Pública

Vincular a avaliação de desempenho à estratégia;

Alinhar os profissionais com uma estratégia mais direcionada para os usuários;

Facilitar, monitorizar e avaliar a implementação da estratégia, fornecendo um feedback contínuo quanto a esta, o que promove ajustes estratégicos regulares;

Facilitar a seleção das iniciativas e otimizar a alocação de recursos;

Comunicar a estratégia a todos os níveis da organização;

Instigar à comunicação e colaboração entre os profissionais;

Atribuir accountability e ajudar a transmitir informação relevante ao público;

Encontrar uma linguagem comum aos diferentes grupos profissionais e facilitar a relação entre a gestão e estes, já que é uma ferramenta simples e multidimensional.

FONTE: Gao E Gurd (2006)

RC: 87947

Disponível em:

https://www.nucleodoconhecimento.com.br/administracao/estrategico-da- 
Todavia, existem questionamentos sobre o BSC, uma vez que existem outros modelos de planejamentos estratégicos no mercado e, muitos anteriores ao BSC, porém é válido destacar que esta ferramenta não é uma simples repetição de conhecimentos, mas trata-se de uma ferramenta que complementa temas novos aos antigos já tratados pela administração, que por diversas vezes estavam esquecidos ou eram mal compreendidos e, principalmente é benéfico por traduzir em suas ferramentas a vinculação entre os pontos vitais de uma gestão eficiente e articulada (CASTRO, 2020).

\section{CONCLUSÃO}

Uma vez analisadas as utilizações do planejamento estratégico nas organizações, em especial no setor público, evidenciam-se que deve, de fato, existir planejamento, pois é de suma importância para a eficiência da gestão e a celeridade das ações.

Outrossim, é notável o protagonismo do BSC em relação ao planejamento, quando está alinhado às ferramentas da gestão, podendo propiciar resultados positivos, seja economicamente ou na qualidade da prestação do serviço, uma vez que estudada a realidade, atinge-se o problema em sua totalidade, e não de forma desordenada.

Logo, conclui-se que o BSC é uma ferramenta de grande valia para a administração pública, mas que ainda necessita ser mais amplamente estudado e estruturado para que gestores amadureçam a ideia da sua utilização, promovendo maior planejamento e ações de aplicabilidade na gestão.

\section{REFERÊNCIAS}

ADMINISTRADORES. Disponível em http://www.administradores.com.br/artigos/ marketing/balanced-scorecard-como-ferramenta-para-o-planejamento-estrategicodecomunicacao-organizacional/26176/. Acesso em 25 fev. 2021.

RC: 87947

Disponível em:

https://www.nucleodoconhecimento.com.br/administracao/estrategico-da- 
BERGUE, Sandro Trescastro. Gestão estratégica de pessoas e balanced Scorecard em organizações públicas. Artigo publicado na Revista Análise - PUC: 2005 nำ 2. Volume 16.

CASTRO, B. A evolução da administração pública. Disponível em: $<$ https://administradores.com.br/artigos/a-evolucao-da-administracao-publica>. Acesso: 24 fev. 2021.

GHELMAN, S.; COSTA, S. R. R. Adaptando o BSC para o setor público utilizando os conceitos de efetividade, eficácia e eficiência. Bauru: XIII SIMPEP, 2006.

KAPLAN, R. S.; NORTON, D. P. A estratégia em ação: Balanced Scorecard. 13. Ed. São Paulo: Campus, 1997.

MARTINS, Tomas S.; GUIDANI, Roberto A; REIS, Júlio Adriano F. dos; CRUZ, June Alisson W. Incrementando a estratégia: uma abordagem Balanced Scorecard. Curitiba. Ibpex, 2010.

MEIRELLES, H. L. Direito administrativo brasileiro. 35 ed. São Paulo: Malheiros editores, 2009.

PRADO, L. J. Guia Balanced score card. 1 ed. IFCURSOS. E-book. Disponível em: $\quad$ http://www.ifcursos.com.br/sistema/admin/arquivos/19-57-39-ebook_balancedscorecard.pdf.

REIS, D. Controle e Avaliação do Planejamento Estratégico no Instituto Federal de Educação, Ciência e Tecnologia Farroupilha. Santa Maria: Universidade Federal de Santa Maria, 2019.

RC: 87947

Disponível em:

https://www.nucleodoconhecimento.com.br/administracao/estrategico-da- 
SANTOS, Â. Evolução dos Modelos de Administração Pública no Brasil. Revista Científica Multidisciplinar Núcleo do Conhecimento. Edição 04. Ano 02, Vol. 01. pp 848-857, Julho de 2017. ISSN:2448-0959

Enviado: Janeiro, 2021.

Aprovado: Junho, 2021.

RC: 87947

Disponível em:

https://www.nucleodoconhecimento.com.br/administracao/estrategico-da$\underline{\text { administracao }}$ 